METALLURGY AND FOUNDRY ENGINEERING - Vol. 38, 2012, No. 1

http://dx.doi.org/10.7494/mafe.2012.38.1.13

\author{
Agnieszka Krawiec*, Paweł Chyła*, Piotr Chyła*, \\ Sylwia Bednarek**, Aneta Łukaszek-Sołek**
}

\title{
NUMERICAL ANALYSIS \\ OF THE INFLUENCE OF LUBRICATION CONDITIONS ON THE FILLING PATTERN IN A COMPLEX PROCESS OF EXTRUDING PARTICULAR HIGH-MELTING MATERIALS
}

\section{INTRODUCTION}

In the process of extrusion, as in all plastic working processes, surface friction has a strong influence on the process. It produces on contact surfaces shear stresses, which influence the pattern of stress, increase strain heterogeneity and substantially increase the extrusion force. In addition, friction increases tool wear significantly. In a process of deformation metal in a container remains under the influence of active and passive forces: punch force, forces of external friction and reactive forces of the tool's still walls. Some of these forces deform metal, and the other impede movement of metal particles one against the other and against the walls of the tool. As a rule, in the process of extrusion in the zone of plastic deformation triaxial compressive stress condition occurs, giving metal in particular conditions best plasticity. Under the influence of compressive stress metal flows in the direction of the greatest stress gradient [1].

However, in extrusion process in the entire volume of the deformed metal the triaxial compressive strain state does not always appear. In fact, as a result of significant differences in cross-sections of a container and a die, external friction and other factors, metal particles flow not only in the direction of greatest strain, but also move in the transverse direction. Besides, during hot extrusion substantial cooling of metal layers that come into contact with walls of the tool occurs. The inner layers having higher temperatures are characterised by better plasticity and are moving faster than the outer layers, which leads also to heterogeneous strain in the metal particles flowing across the section view. Aligning the speed of

* M.Sc., ** Ph.D.: AGH University of Science and Technology, Faculty of Metals Engineering and Industrial Computer Science, Krakow, Poland; e-mail: pchyla@metal.agh.edu.pl 
particles flow of the deformed metal leads to additional tensile stress formation in the outer layers and compressive stress in the inner layers. Additional tensile stresses in the outer layers, with their significant cooling, may be greater than the principal compressive stress. Therefore, in these layers a heteronymous state of stress may occur. Thus, axial stresses at different points in the cross-section of the extruded metal can differ not only in values, but also in character. In the central part there are compressive stresses, while on the outer surfaces there are tensile stresses, which can cause lateral annular tears on the surfaces of low plasticity alloys $[2,3]$.

In this paper, the process of extrusion was analyzed numerically for a axisymmetric forging model where there is a complex material flow diagram (Fig. 1a). The analysis was performed assuming different stoke slenderness ratio, so you can control how to fill the die impression (direct extrusion, indirect and side - Fig. 1b-d), using lubricants with different values of friction factor.

a)

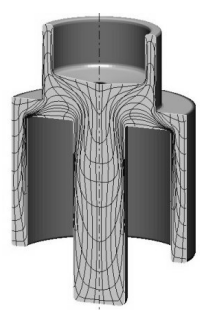

b)

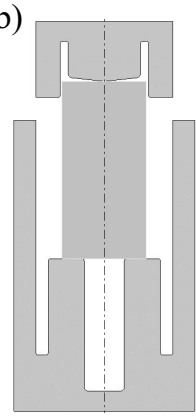

c)

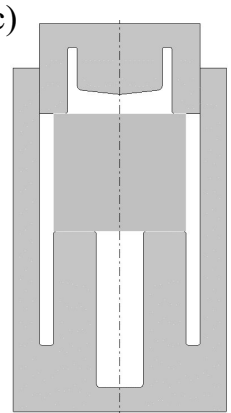

d)

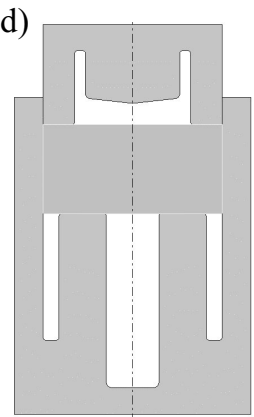

Fig. 1. View of finished forging (a) and billets with slenderness ratio: 2.050 ( $\varnothing 42 \mathrm{~mm}, H 88 \mathrm{~mm})(b)$, 0.875 (Ø $\varnothing 6 \mathrm{~mm}, \mathrm{H49} \mathrm{mm})$ (c) and 0.485 (Ø $68 \mathrm{~mm}, \mathrm{H33} \mathrm{mm})$ (d)

\section{NUMERICAL CALCULATIONS}

Physical and chemical properties of the deformed materials were adopted according to data set for the alloys: titanium Ti-6Al-4V and nickel IN718, assuming a viscoplastic body model, in which plastic flow stress in its simplest form is expressed by the following dependence:

$$
\sigma=f(\varepsilon, \dot{\varepsilon}, T)
$$

where: $\sigma-$ stress, $\varepsilon-$ strain, $\dot{\varepsilon}-$ strain rate, $T$ - temperature.

During the test, different conditions of lubrication were set in order to obtain the best possible effect of die cavity filling in its final stage. In the calculations three values of friction were accepted: 0.08, 0.40, 0.80, both for the lower and upper die, which gave a total of 9 cases of lubrication. Other boundary conditions for the calculations are shown in Table 1. 
Table 1. Summary of boundary conditions of forging

\begin{tabular}{||l|c|c|c||}
\hline \multicolumn{3}{|c|}{ Ti-6Al-4V / Inconel 718 } \\
\hline \multicolumn{1}{|c|}{ Conditions } & Conventional & Isothermal & $\begin{array}{c}\text { Elevated } \\
\text { plasticity [4] }\end{array}$ \\
\hline Ambient temperature, ${ }^{\circ} \mathrm{C}$ & 20 & \multicolumn{2}{|c|}{$900 / 1050$} \\
\hline Stock temperature, ${ }^{\circ} \mathrm{C}$ & \multicolumn{3}{|c|}{$900 / 1050$} \\
\hline Tool temperature, ${ }^{\circ} \mathrm{C}$ & $500 / 600$ & $900 / 1050$ \\
\hline Press speed, mm/s & $10 / 20$ & 1 & 0.01 \\
\hline
\end{tabular}

\section{ANALYSIS OF THE RESULTS OF NUMERICAL CALCULATIONS}

Adopted in numerical calculations lubrication conditions significantly affect the intensity of deformation of the material. The volume of moved material in the concurrent and backward direction depends on the shape and the type of used lubricant.

Inconel 718 has a better filling of the body of die during the deformation process compared to the titanium alloy Ti-6Al-4V (Fig. 2), while the upper arm is filled to a lesser extent. Therefore carried out a detailed observation of the vectors of metal displacement and changes in waveforms of forces in all analyzed variants (54 combinations). Figures 3 to 5 shows some of the curves depending on the relative tools displacement including material flow (vectors of metal displacement).

In the absence of the matrix fill material for the stock of 2.050 and 0.875 slenderness ratio, further discussion was carried out only for stock with 0.485 slenderness ratio. Furthermore, it is most advantageous because of its diameter to fit the width of the die, which in the process eliminated the possibility of eccentric stock placed before the process of deformation (Fig. 6-8).

In the case of deformation adopted for the study alloys of nickel and titanium and stock with 0.485 slenderness ratio can be noticed that the most deformed parts are top and side arms, while the core and the body has been deformed to a lesser extent. This reflects the uneven distribution of deformation in the entire volume of forgings.

Another very important phenomenon is that the forging in closed dies without compensation of metal excess produces in the final stage of forging hydrostatic stress state, very unfavorable to the load of tools, regardless of the conditions of lubrication. Practically, a minimum displacement of tools causes a sharp increase in force. With a precise dosing of lubricant (controlled lubrication), we can reduce the residual value of the shaping force. This problem was analyzed in this work. Figures 9-10 summarizes the values of forces for all the analyzed variants. 
INCONEL 718
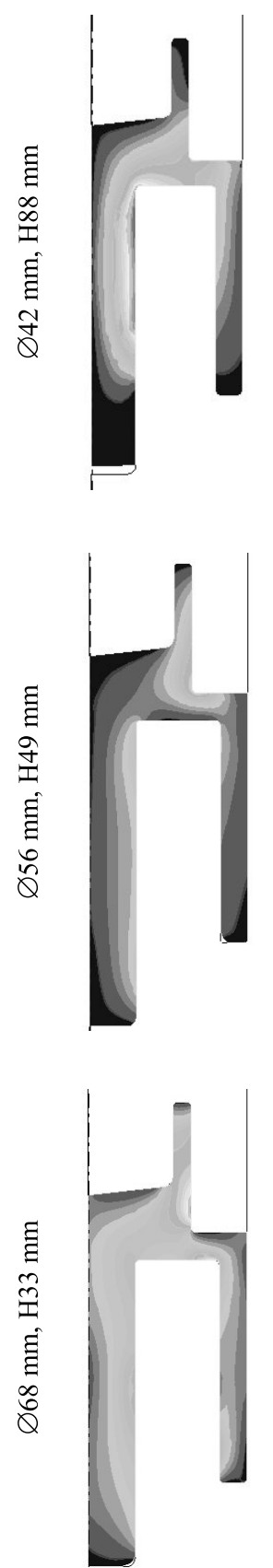

Ti6Al4V
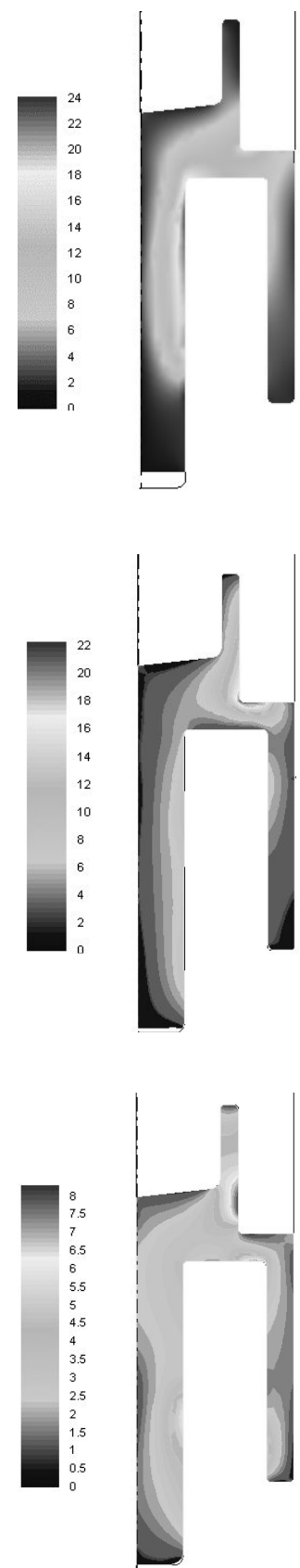

Fig. 2. Sample distribution of effective strain in the axial section of forging for each particular case of lubrication under conditions of elevated plasticity 


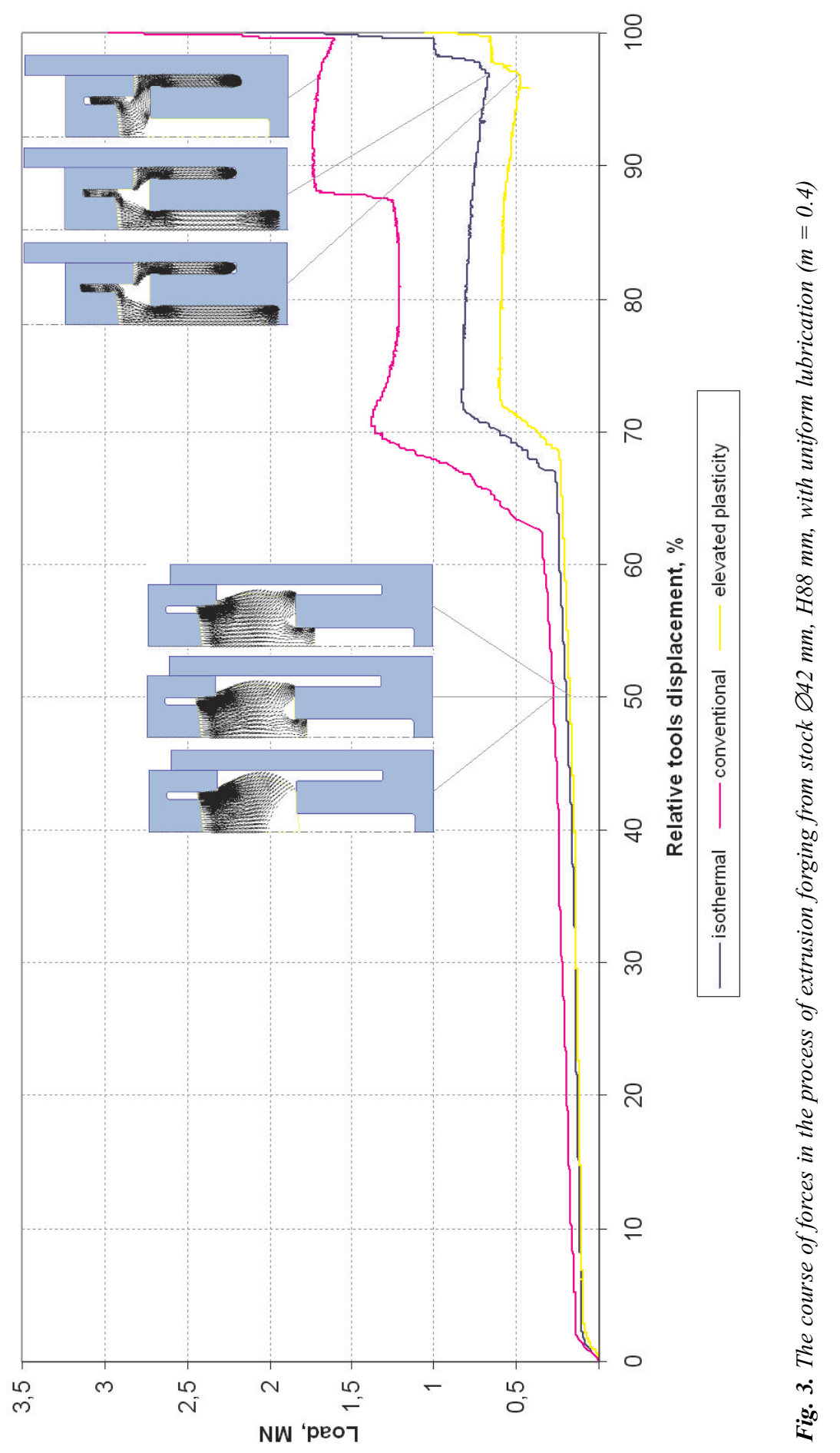




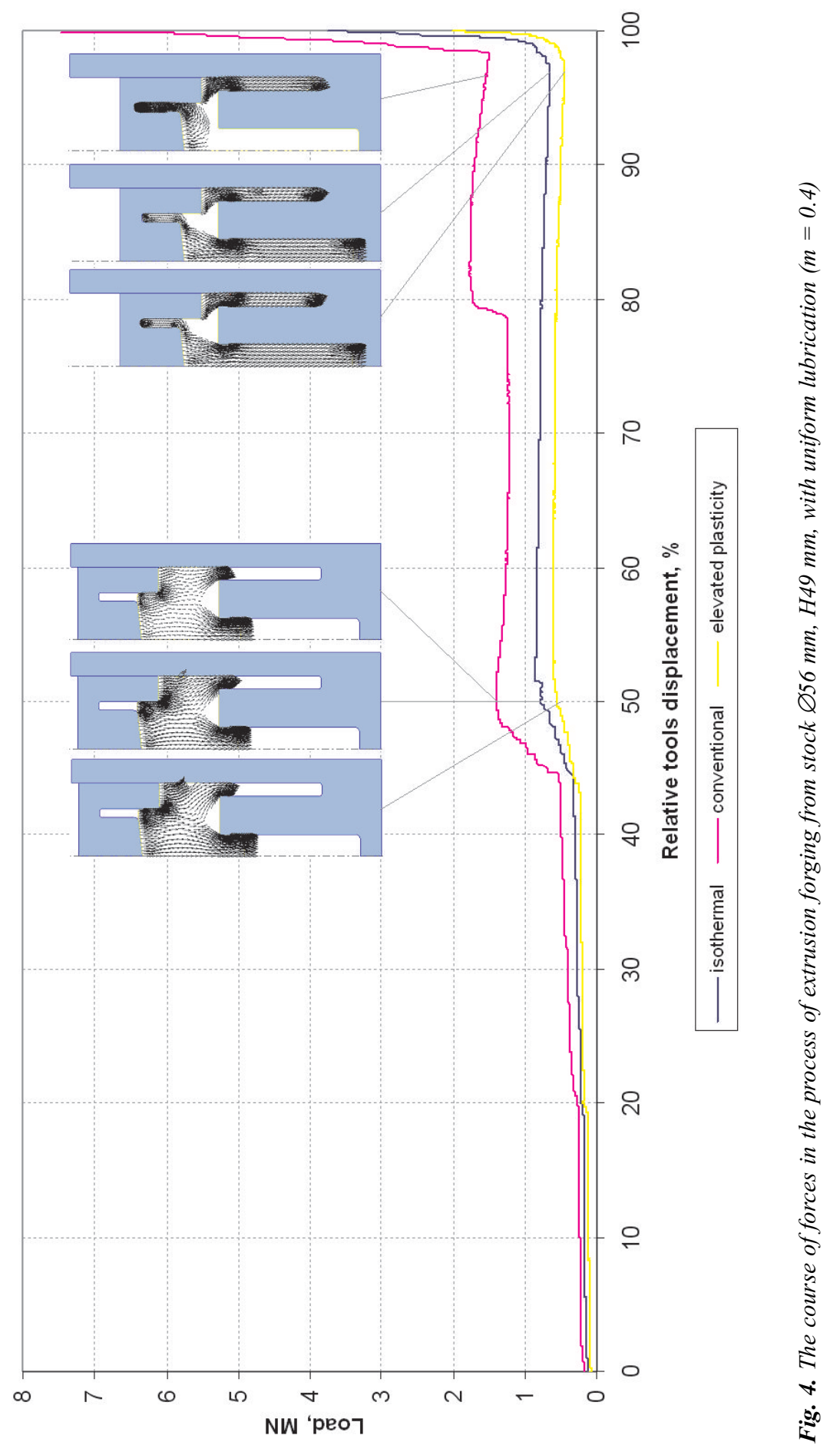




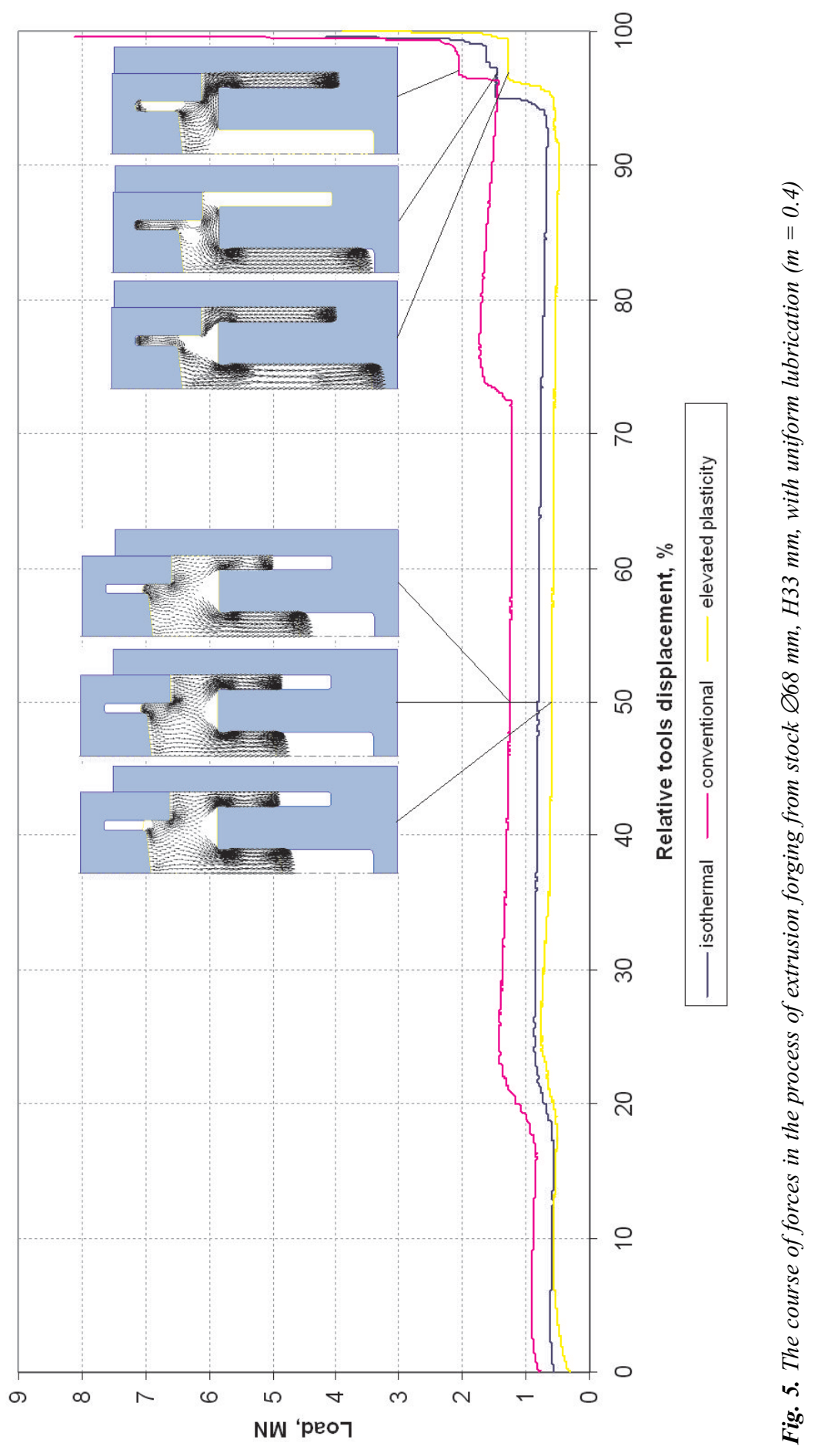


a)

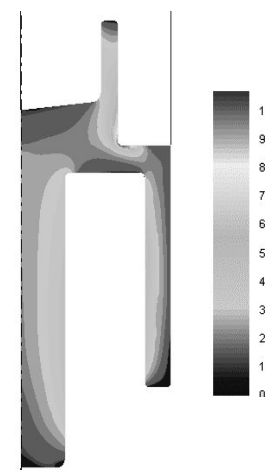

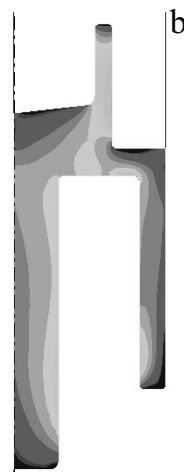

b)
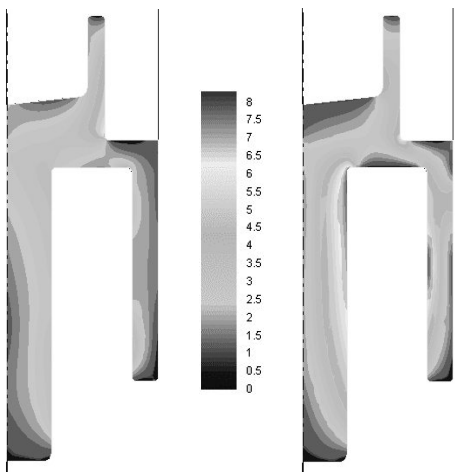

Fig. 6. The influence of lubrication conditions on the strain intensity distribution in the axial section of the forging of titanium alloy (a) and nickel alloy (b) for the characteristic variations of lubrication for forging under conventional conditions

a)

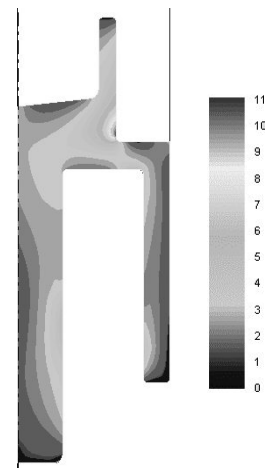

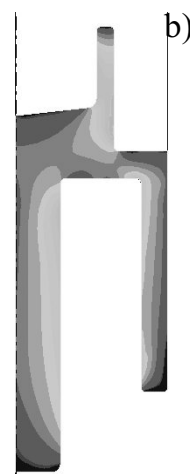

b)
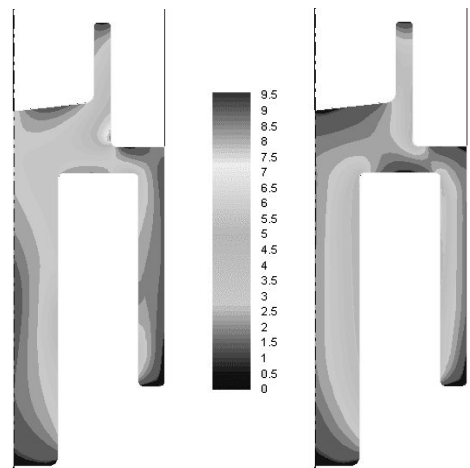

Fig. 7. The influence of lubrication conditions on the strain intensity distribution in the axial cross section of the forging of titanium alloy (a) and nickel alloy (b) for the characteristic variations of lubrication for forging under isothermal conditions
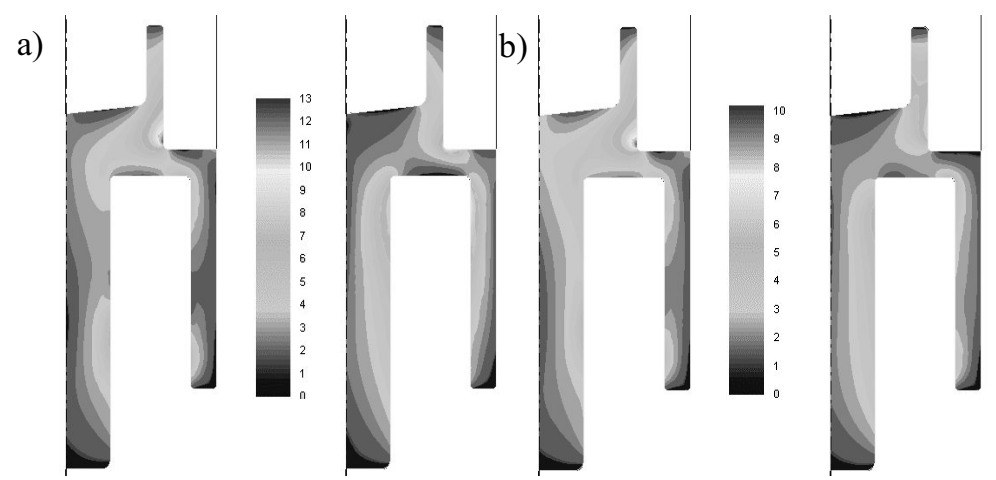

Fig. 8. The influence of lubrication conditions on the strain intensity distribution in the axial cross section of the forging of titanium alloy (a) and nickel alloy (b) for the characteristic variations of lubrication for forging under conditions of elevated plasticity 

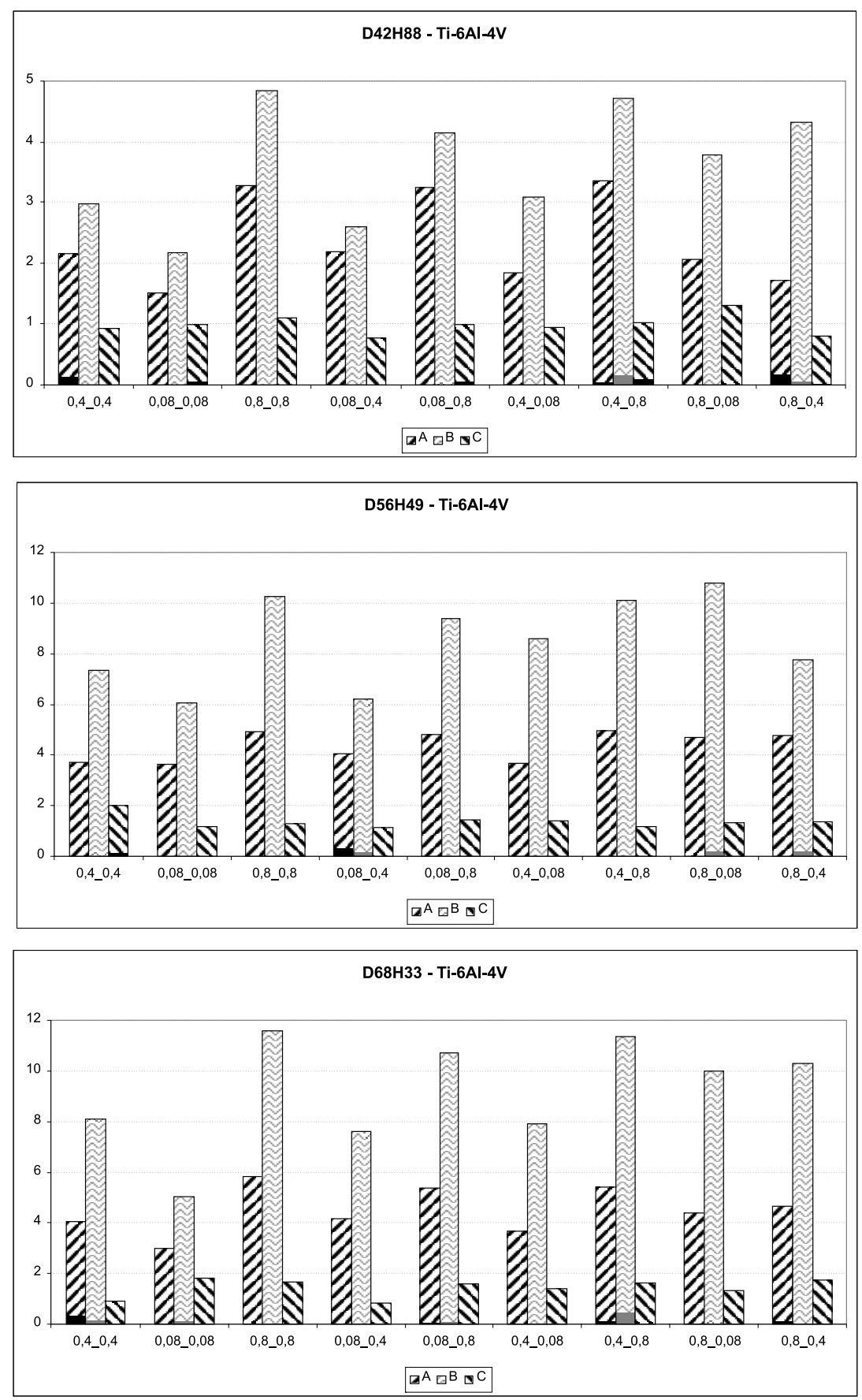

Fig. 9. Dependence of forging conditions on the magnitude of force in the last step, obtained in conditions: $A$-isothermal, $B$ - conventional, $C$-elevated plasticity 

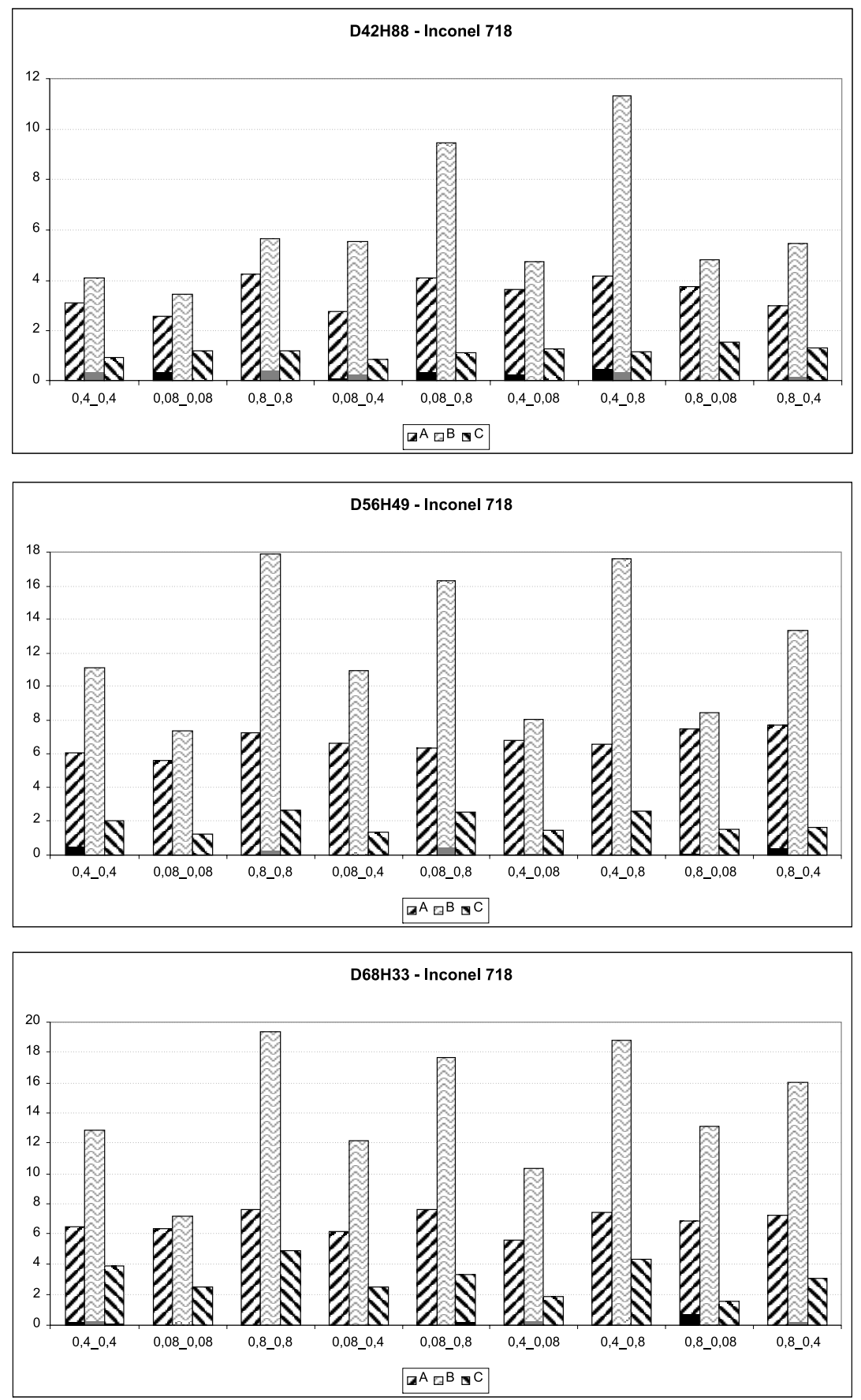

Fig. 10. Dependence of forging conditions on the magnitude of force in the last step, obtained in conditions: $A$-isothermal, $B$ - conventional, $C$-elevated plasticity 
The highest values of forces in the last step of forging occur in conventional conditions (Figs. $3 \div 5,9-10$ ). This is due to large temperature differences between the tool temperature and the temperature of the feed material. This force is several times larger than in the case of forging under isothermal conditions and elevated plasticity.

During forging in conditions of elevated plasticity stock and tools temperature is the

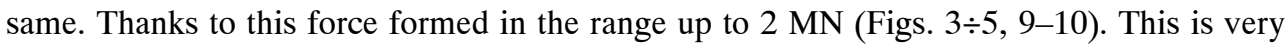
beneficial, using less power classified as a more economical process and deformation of the same stock requires press with smaller nominal force than in the conventional forging. The disadvantage of this option, however, is the long time of deformation.

The method that uses the advantages of the forging process in conditions of elevated plasticity is isothermal forging. Forging temperature of the stock and tools are the same or similar, but the use of more rapid movement of tools, will shorten the forming process. Flow of the material is uniform in the whole volume, however, local overheating can occur especially when forming alloys with high thermal capacity which include titanium alloys.

\section{SUMMARY AND CONCLUSIONS}

In the performed numerical calculations of the process of forging two alloys significantly different characteristics of the stress as a function of strain, strain rate and temperature it was found that these materials have high sensitivity on lubrication conditions. This manifested itself in the way of flow in die impression during the forging of very complex shape forging where the main means of impression filling is extrusion. It is expected (in industrial practice) also a similar flow of these alloys in making forgings with shapes corresponding to the analyzed model.

During nickel alloys deformation in conventional forging conditions were received in the last stage of forging at high gradients of temperature and high loads. Mean stress value exceeds $-1500 \mathrm{MPa}$ which may cause the overloading of tools. For the titanium alloy mean stresses are lower, according to its characteristics also associated with the deformation in the temperature range, it is capable of two phases.

Using deformation under isothermal conditions half lower loads in comparison with conventional forging were obtained.

For die impressions with a high degree of complexity, especially when the die is filled with metal in the complex process of extrusion, it is desirable for the analysis of metal flow based on numerical calculations. This allows us to apply the most favorable conditions for the forging process without running very expensive industrial tests for the development of technology forging of titanium and nickel alloys. This applies above all lubrication conditions including controlled lubrication involving the use of lubricants with different properties of lubricantion to the appropriate areas of the die impression. 


\section{Acknowledgements}

Financial support of Structural Funds in the Operational Programme - Innovative Economy (IE OP) financed from the European Regional Development Fund - Project No WND-POIG.01.03.01-12-004/09 is gratefully acknowledged.

\section{REFERENCES}

[1] Behrens A., Schafstall H.: 2D and 3D simulation of complex multistage forging processes by use of adaptive friction coefficient, J. Mat. Proc. Technol., 80-81 (1998)

[2] Sheljaskow S.: Tool lubricating systems in warm forging, J. Mat. Proc. Technol., 113 (2001)

[3] Borsellino C., Micari F., Rusi V.F.: Warm compression of aluminium alloy axisymmetric rings, Adv. Techn. of Plasticity., 1 (1999)

[4] Sińczak J., Bednarek S.: Fizyczne i numeryczne modelowanie procesu kucia dwufazowych stopów tytanu w warunkach izotermicznych. Prace Naukowe / Politechnika Warszawska. Seria: Mechanika, (2007), 216, 59-66

Received

December 2011 